\title{
Extraction and standardization of betalain from $C$. argentea var. cristata
}

\section{- RAHUl RAMRAO PATIL* AND T. V. RANGANATHAN}

Department of Bioscience and Technology, Food Processing and Engineering, School of Agriculture and Biosciences, Karunya Institute of Technology and Sciences, COIMBATORE (T. N.) INDIA

Email: rahulpatil2407@gmail.com

SUMMARY :

In the current work, studies were carried out to extraction and standardization of the betalains from Celosia argentea var. cristata (CAC) inflorescence for possible use as a source of natural colour for the food industry. Pigment extraction was carried out using water as the extractant. Results showed that maximum betacyanins were extracted at a $\mathrm{pH}$ of 5 using citrate buffer, at a sample: solvent ratio of $1: 3$, the temperature of $20^{\circ} \mathrm{C}$ for 90 minutes. The extracted pigments were found to stable at $4^{\circ} \mathrm{C}$ upto 15 days.

KEY WORDS : Betalain, Pigment, Natural colour

How to cite this paper : Patil, Rahul Ramrao and Ranganathan, T. V. (2017). Extraction and standardization of betalain from $C$. argenteavar. cristata. Internat. J. Proc. \& Post Harvest Technol., 8 (2) : 123-130. DOI: 10.15740/HAS/IJPPHT/8.2/123-130. 